\title{
CONSIDERAÇÕES SOBRE JUSTIÇA DE TRANSIÇÃO NO ESTADO NOVO
}

\section{CONSIDERATIONS ON TRANSITION JUSTICE IN THE ESTADO NOVO}

DOI: http//dx.doi.org/10.15448/2178-3748.2017.2.27440

Enio Viterbo Martins

Mestrando em História do Brasil (Universidade Salgado de Oliveira)

enio0504@gmail.com

RESUMO: O objetivo do presente estudo é analisar os fatores que levaram a falta de uma justiça transicional referente ao regime ditatorial do Estado Novo e sua transição para o governo democrático do General Dutra. As bases teóricas serão dadas através de uma abordagem interdisciplinar com utilização de Direito e História comparada com a Itália pós Mussolini, conceituação de Justiça de Transição e breve análise dos crimes da polícia política do Estado Novo.

PALAVRAS-CHAVE: Justiça de Transição. Estado Novo. Ditadura.

ABSTRACT: The objective of the present study is to analyze the factors that led to the lack of a transitional justice regarding the Estado Novo dictatorial regime and its transition to the democratic government of General Dutra. The theoretical bases will be given through an interdisciplinary approach using Law and History compared to Italy after Mussolini, conceptualization of Transitional Justice and brief analysis of the crimes of the Estado Novo political police.

KEYWORDS: Transitional Justice. Estado Novo. Dictatorship.

\section{Introdução}

A Era Vargas, apesar de na seara das relações de trabalho ser lembrado como um época importante na construção de um arcabouço jurídico de proteção aos direitos trabalhistas, foi responsável por inúmeras violações aos direitos humanos e fundamentais tanto antes quanto depois da implementação do regime autoritarista do Estado Novo.

Através de sua polícia política, a Delegacia Especial de Segurança Política e Social DESPS, o Estado Novo prendeu, perseguiu, torturou e assassinou opositores civis e militares, podendo ser citados como exemplos de tal perseguição política a prisão de Luis Carlos Prestes e do infame caso da tortura do alemão Harry Berger, defendidos em diferentes ocasiões pelo 
advogado Sobral Pinto (que chegou inclusive a citar leis de proteção aos animais para defender Harry Berger, devido a intensa tortura que lhe acometia a polícia política).

A questão apresentada no presente trabalho é que diferente do contexto internacional do pós-guerra no cenário europeu, onde houveram formas de punir os agentes dos estados fascistas que foram autores de crimes contra os direitos fundamentais, não houve uma justiça transicional que buscasse responsabilizar e prender os agentes estatais varguistas que cometeram tais atrocidades contra os direitos humanos no cenário brasileiro, ao que este presente estudo credita ser devido a uma falta de vontade política da oposição ao regime varguista.

A metodologia utilizada para o estudo leva em consideração a doutrina jurídica sobre justiça de transição, a analise através de Direito e História comparada com a Itália pós Mussolini, além da uma breve consideração histórica a respeito do fim do Estado Novo para que seja possível analisar como uma chamada "transição pactuada" pode ter sido responsável por não ter ocorrido a responsabilização penal dos agentes estadonovistas que perpetuaram crimes contra os direitos humanos.

\section{Justiça de Transição}

Justiça de Transição são os meios pelos quais um governo democrático pode realizar reparações a sociedade por danos sofridos por governos ditatoriais anteriores a este novo regime democrático, ou seja, são mecanismos que variam desde ações penais para responsabilização dos agentes do Estado ditatorial que cometeram crimes como tortura, desaparecimento forçado ou assassinatos contra a sociedade civil, bem como ações de natureza mais institucionais, tais como Comissões Nacionais (ou estaduais) da Verdade, ou ainda reparações indenizatórias as vítimas dos referidos agentes estatais.

Este conceito de justiça de transição original atualmente foi expandido para novas situações onde são abarcados novos tipos de circunstâncias extraordinárias como, por exemplo, casos de violações aos direitos humanos que não sejam cometidos pelo Estado, como ocorreram nos episódios de conflitos civis generalizados em alguns países africanos, cite-se ainda as situações onde não existe um regime democrático anterior ao período ditatorial para que a justiça de transição possa utilizar-se de referencia para suas práticas (TORELLY, 2015) ${ }^{1}$.

\footnotetext{
${ }^{1}$ TORELLY, Marcelo. Justiça de Transição - Origens e Conceitos. In: SOUSA JUNIOR, J. G. (Org.); SILVA FILHO, J. C. M. (Org.); PAIXAO, C. (Org.); FONSECA, L. G. D. (Org.) ; RAMPIN, T. T. D. (Org.) . O Direito Achado na Rua: introdução crítica à justiça de transição na América Latina. 1. ed. Brasília.2015. v. 1.
} 
Existe, no entanto, uma corrente minoritária que atribui uma crítica no próprio âmago da discussão conceitual desta forma de justiça, referindo-se que se a democracia já está instaurada no período pós-ditadura não há de se falar em transição alguma e as próprias práticas de justiça de transição nada mais seriam do que formas "ordinárias" de justiça e não teriam qualquer arcabouço teórico próprio e distinto, o que tornaria prejudicado o próprio conceito de justiça de transição (WINTER, 2013, p.225)².

Os mecanismos de justiça de transição que objetivam a reconciliação nacional são diversos entre os países que percorreram o caminho de uma ditadura, os governantes democráticos podem optar dentre ações penais para prender os agentes estatais envolvidos em violações de direitos humanos, comissões da verdade, programas de reparação as vítimas, justiça de gênero, reforma do sistema de segurança, efetivação do direito à memória, além de outras medidas de integração, reconciliação e reparação da sociedade pelo período autoritário sofrido.

Apesar de existirem vozes ${ }^{3}$ que afirmam que podemos encontrar traços da justiça de transição que retornam até ao período da Revolução Francesa, geralmente se atribui a origem da atual forma da justiça de transição, no tocante a prisão de agentes estatais que cometeram crimes contra os direitos humanos e fundamentais, no período pós-segunda guerra mundial, através dos tribunais internacionais de Nuremberg e Tóquio, que julgaram quatro modalidades de acusações, conforme Arnaldo Vieira Sousa (2015, p.173): “1 - Conspiração e atos deliberados de agressão; 2 - Crimes contra a paz; 3 - Crimes de Guerra; e 4 - Crimes contra a Humanidade." 4 .

Conforme anteriormente citado, por serem amplos os mecanismos utilizados pela justiça de transição, uma das formas encontradas pelos países europeus que atravessaram regimes ditatoriais, especificamente Alemanha e Itália, foi realizar um expurgo na administração pública de indivíduos identificados com os antigos regimes além de desnazificação e desfascistização das sociedades civis alemães e italianas.

No cenário de guerra europeu, Mussolini foi demitido pelo rei Emanuel III ainda em 25 de Julho de 1943, a população começou a atacar os símbolos do regime fascista, tais como retratos de Mussolini, monumentos e etc..., porém, inicialmente, o novo governo realizou

\footnotetext{
${ }^{2}$ WINTER, Stephen. Towards a Unified Theory of Transitional Justice. The International Journal Of Transitional Justice, Volume 7 (2), p. 224-244. 2013.

${ }^{3}$ STEINBERG, Ronen. Transitional Justice in the Age of the French Revolution. International Journal of Transitional Justice. 2013.

${ }^{4}$ SOUZA VIEIRA, Arnaldo. Nuremberg e os crimes contra a humanidade. In: SOUSA JUNIOR, J. G. (Org.) ; SILVA FILHO, J. C. M. (Org.); PAIXAO, C. (Org.); FONSECA, L. G. D. (Org.); RAMPIN, T. T. D. (Org.) . O Direito Achado na Rua: introdução crítica à justiça de transição na América Latina. 1. ed. Brasília. 2015.
} 
poucas medidas de saneamento dos fascistas da administração pública e sequer dissolveu a polícia política fascista.

A demissão de Mussolini pelo rei a 25 de julho de 1943 foi determinada por um golpe interno e se, por um lado, comprovava a frustração do povo italiano com as mortes e os sacrifícios sofridos a combater numa guerra indesejada, por outro, teve apenas um efeito marginal sobre a continuidade institucional do regime. ${ }^{5}$

Entretanto, com a pressão da sociedade civil e de partidos políticos antifascistas, o novo governo foi obrigado a utilizar-se de medidas de transição mais incisivas para expugar da administração publica aqueles funcionários identificados com o antigo regime autoritário. Como esclarecer Marco Tarchi: "Foram criadas comissões, que incluíam vítimas das perseguições políticas do fascismo, para analisar a posição de todos os suspeitos. O seu objetivo era identificar aqueles que podiam participar na reconstrução democrática do país e aqueles que deviam ser excluídos."

Posteriormente, em 1945, em um contexto de fim da guerra no cenário europeu, começou uma fase transicional italiana onde ocorreram diversas execuções sumárias de indivíduos ligados ao regime fascista, com números estimados entre 12 e 15 mil mortes, demonstrando-se assim que a desconstrução do regime autoritário ainda estava em vigor no imaginário político italiano.

Assim, pode-se considerar, tendo em vista o contexto internacional, principalmente no cenário Europeu, que uma que o regime autoritário de Vargas encerrou-se em 1945, quando foi deposto por um golpe liderado pela cúpula militar e começou o regime democrático com o governo do General Eurico Gaspar Dutra, os mecanismos de justiça de transição seriam plenamente aplicáveis à realidade brasileira.Contudo, os agentes da polícia política de Vargas que torturavam, prendiam e assassinavam livremente os oposicionistas, não foram presos ou sequer indiciados.

\section{FORMASDE TRANSIÇÃO}

\footnotetext{
5 TARCHI, Marco. O passado fascista e a democracia na Itália. In: COSTA PINTO, Antonio. PALOMANES MARTINHO, Francisco Carlos(Org). O passado que não passa: a sombra das ditaduras na Europa do sul e na América Latina. Rio de Janeiro: Civilização Brasileira, 2013, p. 48.

6 TARCHI, Marco. Op Cit. p. 53
} 
A doutrinajurídica acerca de Justiça de Transição atesta a existência de dois tipos de transiçãode um governo ditatorial rumo a um novo governo democrático: A transição "pactuada" e a transição "por ruptura" (MACHADO COSTA, 2013)7.

$\mathrm{Na}$ transição "pactuada"a elite política do regime autoritário conduz a transição para a o regime democrático.Tal condução lhe permite manter-se na administração pública enquanto as novas instituições democráticas vão sendo formadas, deste modo, a antiga elite política do regime autoritário pode participar ativamente no novo governo democrático sucessor. ${ }^{8}$

Esta elite se organiza a fim de que também não haja um processo de responsabilização transicional a seus agentes estatais, de modo que as suas práticas abusivas e autoritárias sejam deixadas impunes.Como prossegue Antonio Costa Pinto (2013, p.24): "Em transições por reforma, nas quais a elite autoritária é um parceiro poderoso no processo de transição, o espaço para a introdução de medidas retributivas é limitado."

De tal modo, tanto a qualidade dos políticos profissionais com valores autoritários e baixos níveis de lealdade com a democracia quanto a continuidade das elites politicas anteriores no controle das novas instituições democráticas, geram uma falta de confiança da população nas elites, de modo que estas são identificadas com o regime anterior e a credibilidade da nova democracia fica seriamente abalada ${ }^{10}$

$\mathrm{Na}$ transição dita "(transição)de ruptura" a oposição de um governo ditatorial consegue concretizar a transição para o governo democrático retirando a elite politica ditatorial do novo governo democrático, quando não, como em muitos casos, elimina a própria existência física desta mesma elite.

São nas transições por ruptura que geralmente podemos encontrar uma maior probabilidade do regime democrático buscara responsabilização penal dos agentes estatais autoritários, pois neste tipo de transição a nova elite política busca eliminar os laços ideológicos e institucionais com o antigo regime. De modo contrário, na transição pactuada existe uma maior probabilidade de encontrarmos uma certa tolerância ou mesmo impunidade com os

\footnotetext{
${ }^{7}$ MACHADO COSTA, Patricia da. Transições pactuadas e transições por ruptura: a manutenção do legado autoritário no Brasil e sua influência no processo de justiça transicional. Aedos, UFRGS. no 13 vol. 5 - Ago/dez 2013, Disponível em: http://seer.ufrgs.br/index.php/aedos/article/viewFile/42203/28048. Acesso em: 14 de Dez de 2017

${ }^{8}$ VITERBO MARTINS, Enio. A Transição Democrática Imposta E Sua Relação Com A Justiça De Transição. Revista da EMARF, Rio de Janeiro, v.26, n.1, p.1-294, mai./out.2017, p. 79.

COSTA PINTO, Antonio. O passado autoritário e as democracias da Europa do Sul: uma introdução. In: COSTA PINTO, Antonio. PALOMANES MARTINHO, Francisco Carlos (Org). O passado que não passa: a sombra das ditaduras na Europa do sul e na América Latina. Rio de Janeiro: Civilização Brasileira, 2013, p. 24.

${ }^{10}$ VITERBO MARTINS, Enio. Op. Cit., p. 83.
}

Oficina do Historiador, Porto Alegre, EDIPUCRS, v. 10, n. 2, jul./dez. 2017, 
agentes estatais do regime autoritário, vide a experiência brasileira pós regime militar 19641985 .

De maneira geral, quando a transição é feita pela via pactuada, existe uma maior tolerância na punição sobre os agentes estatais da ditadura anterior, tendo em vista que grande parte da administração publica ainda se encontra lotada de funcionários do antigo regime que dependendo do posto que ocupem acabam exercendo forte influencia sobre as práticas da justiça de transição em seu país. ${ }^{11}$ (sic)

Portanto, considerando as formas de transição, podemos identificar que a transição Italiana foi de ruptura, pois a demissão de Mussolini do governo em 1943, quando começa uma fase incial de justiça de transição na Itália, foi agravada em 1945 quando Mussolini é executado, a República Social Italiana é dissolvida e começam inúmeras mortes de agentes estatais ligados ao fascismo, julgamentos destes mesmos agentes e um movimento da população de demonstração de sua rejeição ao regime autoritário juntamente com os partidos políticos oposicionistas conseguindo eliminar grande parte do aparato estatal fascista herdado do regime anterior.

Por fim se por um lado houve um grande esforço, a partir de uma transição de ruptura, por parte da sociedade italiana em buscar a responsabilização dos agentes estatais identificados com o fascismo e que cometeram crimes contra a própria população civil, por outro, em um mesmo contexto de fim de segunda guerra e de uma onda curta mundial de democratização ${ }^{12}$, o mesmo não se repetiu na transição pactuada que ocorreu em 1945 no Brasil com a deposição de Vargas pela cúpula militar representada por Góes Monteiro e Eurico Gaspar Dutra, apoiada pela UDN.

Assim sendo, faz-se necessário uma breve análise sobre a repressão da polícia política varguista, além de sua própria organização administrativa e histórico institucional.

\section{Crimes do Estado Novo}

\section{A organização e antecedentes da polícia política da ditadura}

Antes da Era Vargas os seguintes dispositivos legais regulamentavam a atuação da polícia política do Distrito Federal: Decreto no 3.610 de 14 de abril de 1900; Decreto ${ }^{\circ} 6.440$ de 30 de março de 1907; Decreto nº 14.079 de 25 de fevereiro de 1920 (vale notar que neste decreto primeira vez é criada uma seção interna de polícia política para exclusivamente

\footnotetext{
${ }^{11}$ Ibdem. p. 83-84.

12 Disponível em: https://www.ned.org/docs/Samuel-P-Huntington-Democracy-Third-Wave.pdf. Último acesso em: 14 de Dez de 2017.
} 
monitorar a "Ordem Social e Segurança Pública"13); e por fim, antes de adentrarmos no período da Era Vargas, temos o Decreto 15.848 de 20 de novembro de 1922.

Durante o período varguista o Decreto $\mathrm{n}^{\mathrm{o}} 22.332$ de 10 de janeiro de 1933 cria especificamente um órgão encarregado da polícia política: a Delegacia Especial de Segurança Política e Social (DESP). Esse órgão foi formado dentro da Polícia Civil do Distrito Federal, porém respondia diretamente ao chefe de polícia civil do Distrito Federal.

Inicialmente a polícia era chefiada por Batista Luzardo e após este ter sido exonerado do cargo em 1932, no ano seguinte, 1933, ela começa a ser liderada por Filinto Müller.

Subordinado ao Sr. Filinto Müller, estavam a Delegacia de Ordem Política, chefiada pelo Sr. Serafim Braga, e a Delegacia de Ordem Social, chefiada pelo Sr. Emílio Romano.

Em seguida, o Decreto-Lei no 6378, de 28 de março de 1944: Transforma a Polícia Civil do Distrito Federal em Departamento Federal de Segurança Pública (DFSP), com atribuições nacionais e locais.

E finalmente, com o Decreto $\mathrm{n}^{\circ}$ 17.905, 27 de fevereiro de 1945 temos o último decreto que regulamentava a administração da Polícia no Distrito Federal durante o governo Vargas, este decreto aprovava o Regimento do DFSP. Tal Decreto define os crimes contra segurança política como "os praticados contra a estrutura e a segurança do Estado".

\section{A repressão da polícia política}

Nesse tópico analisaremos como a repressão política e as violações aos direitos fundamentais no Brasil de maneira sistemática tiveram início no governo Vargas ainda em período anterior ao Estado Novo, esclarecendo que, obviamente, a situação agrava-se com advento do golpe de 10 de Novembro de 1937.

A apresentação das violações aos direitos humanos da polícia do regime varguista é imprescindível para que se possa auferir responsabilização aos agentes estatais perpetuadores de tais crimes e se tais crimes tratavam-se de uma política de Estado.

Todavia, não creditamos a Vargas a criação deste aparato repressor político, sendo tal aparato anterior a seu início de governo. Conforme o art. $5^{\circ}$ inciso III do Decreto ${ }^{\circ} 14.079$ de

\footnotetext{
${ }^{13}$ Conforme o art. $5^{\circ}$ inciso III: “A Secção de Ordem Social e Segurança Publica tem a seu cargo velar pela existencia politica e segurança interna da Republica, attender por todos os meios preventivos á manutenção da ordem garantir o livre exercicio dos direitos individuaes, nomeadamente a liberdade de trabalho, desenvolver a maxima vigilancia contra quaesquer manisfestações ou modalidades do anarchismo violento e agir com solicitude para os fins da media de expulsão de estrangeiros perigosos" (sic).
} 
25 de fevereiro de 1920,já existia um órgão direcionado a segurança política do regime vigente, e ainda como preconiza Thiago da Silva Pacheco (2010, p.127-128):

A construção deste aparelho antecede a ascensão de Getúlio Vargas ao poder em 1930. A primeira tentativa de estruturar um sistema de inteligência capaz de municiar o governo com informações precisas acerca do andamento da atividade subversiva e de segurança nacional ocorre durante o governo de Washington Luís, com a criação, em 1927, do Conselho de Defesa Nacional. Todavia, tal órgão limitava-se uma reunião confidencial entre ministros de Estado para troca de informações, não apresentando condições operacionais para a atividade de inteligência ${ }^{14}$

Contudo, Vargas se vale especialmente da Policia do Distrito Federal,mais especificamente da DEPS, para assegurar sua repressão desmedida,inclusive esta polícia fornecia o aparato técnico epossuía a infraestrutura necessária para a opressão do regime autoritário varguista. Prossegue Thiago Pacheco(2010. p.135-136):

[...] a DESPS concentra em si toda a atividade repressiva ligada a segurança nacional. Ela é responsável pela Inteligência (infiltrando espiões, efetuando escutas telefônicas, produzindo fichas e prontuários, analisando as informações recolhidas, entre outras coisas), pela atuação investigativa (utilizando o aparato policial típico da policia civil) e pela repressão direta (buscas, apreensões, campanas, interrogatórios, sindicâncias, etc.). Todo o processo repressor no Estado Novo, desta maneira, começa e termina na Delegacia Especial de Segurança Política e Social. ${ }^{15}$

Saliente-se que as violações aos direitos humanos e constitucionais da polícia varguista começaram de forma sistemática, antes mesmo de implantada a ditadura do Estado Novo. Citamos como exemplo o caso do deputado federal Domingos Velasco que foi detido em casa no dia 23 de março de 1936 e permaneceu preso mais de um ano sem que fosse apresentada uma simples acusação.Transcrevemos Nelson Werneck Sodré (2010,p.337):

A polícia matava nas ruas, invadia as casas a qualquer hora, inventava histórias, forjava documentos, arquitetava conspirações, torturava testemunhas e acusados. Instituiu-se, no melhor modelo fascista, a delação como norma de conduta, instalou-se o processo de denúncia sob qualquer pretexto, retirou-se ao cidadão o direito de escrever, de falar, de reunir-se com outros, de criticar, de protestar, de discutir, de conversar, de divergir. Foi a mais longa noite de terror que este país já conheceu. ${ }^{16}$

\footnotetext{
${ }^{14}$ PACHECO DA SILVA, Thiago. As duas faces da repressão: semelhanças e diferenças da polícia política durante o estado novo (1937-1945) e durante a ditadura militar (1964-1983). Revista de História Comparada, Rio de Janeiro, 2010.

${ }^{15}$ PACHECO DA SILVA, Thiago. Op. Cit, p. 135-136.

${ }^{16}$ SODRÉ, Nelson Werneck. História Militar do Brasil/Nelson Werneck Sodré, 2 ${ }^{\mathrm{a}}$ Ed. São Paulo: Expressão Popular, 2010, p. 337.
} 
Ainda em 1936 temos a criação do "Tribunal de Segurança Nacional”, tribunal de exceção justificado como órgão da Justiça Militar que tinha por competência julgar crimes políticos. Note-se que este tribunal foi criado pela lei nº244 de 11 de Setembro de 1936,antes mesmo da formação do Estado Novo, e só foi ter respaldo constitucional em 1937.

Atestando o caráter sistemático das violações aos direitos humanos, começa durante o período do Estado Novo a prática de se aprimorar técnicas de tortura,observando que o jornalista David Nasser afirma que foram contratados técnicos da Europa para supervisionar as torturas perpetradas pela polícia política (NASSER, 1966. p.61).

\section{Fim do Estado Novo}

Finda a apresentação dos crimes políticos e comuns cometidos pela policia varguista, adentremos como foi o período pós Estado Novo e como se deu a relação de transição entre o período ditatorial e a redemocratização do Brasil.

Getúlio Vargas começa no final do seu governo a tomar medidas tidas como demagógicas pela oposição, supostamente com intuito de prorrogar sua manutenção no poder. O presidente inicia o dialogo com setores da sociedade que exigiam a volta da democracia, já que o Brasil tinha ido à guerra justamente para lutar por esse sistema de governo inexistente no próprio país, porém não deixa também de dialogar com sua base sindicalista e popular que exigia sua manutenção no poder, dando força ao movimento "Queremista".

Vargas então dá sinais que está disposto a anistiar os comunistas presos nos porões da ditadura em troca de um apoio de Prestes ao seu projeto de governo, porém tal anistia tinha com uma restrição, não seria possível reincorporar os militares expulsos das forças armadas condenados pelo levante comunista de 1935

Coincidentemente logo depois de promulgada, em abril de 1945, a anistia aos presos políticos, Prestes afirma que a substituição de Vargas por outro líder de governo seria benéfico aos fascistas, indicando que o Partido Comunista Brasileiro apoiaria a manutenção de Getúlio no poder.Cite-se o próprio Prestes (1945. p.22-23):

A oposição exige que o sr. Getulio Vargas abandone o cargo, para que seja mantida a paz interna. Mas será êsse realmente o caminho democrático da ordem, da paz, e da união nacional? Não terá, ao contrário, razão o sr. Getúlio Vargas ao afirmar que seu dever é manter a ordem para levar o país a eleições livres e honestas e entregar o poder ao eleito da Nação? Sua saída do poder neste instante seria uma deserção e uma traição que não contribuiria de forma alguma para a União Nacional; pelo contrário, despertaria novas esperanças 
entre os fascistas e reacionários e aumentaria as dificuldades, tornando mais ameaçador ainda o perigo de golpes de estado e de guerra civil.(sic) $)^{17}$

Levantamos a hipótese de que o conveniente esquecimento do ranço histórico entre a oposição comunista e o governo varguista era importante tanto para Vargas quanto para os comunistas, pois estes não poderiam buscar a responsabilização dos agentes perpetuadores dos crimes contra os direitos humanos do governo ditatorial devido à possibilidade que a UDN e os laços mais conservadores da sociedade se aproveitassem do enfraquecimento de Vargas e desgastando ainda mais o presidente, tivessem uma grande oportunidade nas futuras eleições.

Ainda no processo transicional, em maio de 1945, é assinado o Decreto-Lei no 7.586 , a "Lei Agamenon", que buscava regularizar o processo eleitoral marcado para o final daquele ano e evitar que partidos políticos regionais voltassem a ter grande influencia, estabelecendo a necessidade de uma composição nacional dos partidos políticos que desejassem participar das eleições. Vargas estava expressamente regulando a transição de seu regime autoritário para o novo governo democrático que viria a ser eleito.

Neste momento a transição do cenário brasileiro foi de certa forma "pactuada" considerando que apesar do Estado Novo ser tido fim através de um movimento das forças armadas, os partidos políticos dominantes, tanto a UDN quanto PSD, não só não promoveram quaisquer saneamentos na administração publica de elementos ligados ao Estado Novo varguista, como também não buscaram, da forma incisiva a exemplo da transição Italiana que estava ocorrendo no cenário Europeu, a responsabilização criminal dos agentes da polícia política varguista, devido, ao que acreditamos, serem dois fatores.

Como $1^{\circ}$ fator, os partidos políticos demonstravam-se mais interessados em lançar um candidato próprio que alcançasse a presidência ou possivelmente compor o governo eleito, do que realizar um saneamento no mecanismo autoritário anterior. Exemplo disso é de que o candidato do PSD, Gaspar Dutra, foi apoiado pelo próprio Getúlio Vargas em detrimento do candidato da UDN, Eduardo Gomes.

A própria UDN, que capitalizava a oposição ao Estado Novo, iria compor a base do Governo Dutra através dos seguintes Ministérios: Raul Fernandes tornou-se o ministro das Relações Exteriores, Clemente Mariani, ministro da Educação e Saúde e Daniel Carvalho, do Partido Republicano aliado da UDN, ministro da Agricultura.

Maria Benevides (1981, p. 52) demonstra que a oposição que a UDN mostrou para a elite política seria mais como uma opção viável e não propriamente como uma instituição

${ }^{17}$ PRESTES, Luiz Carlos. UNIÃO NACIONAL para a democracia e o progresso. Rio de Janeiro, 1945, p.22-23.

Oficina do Historiador, Porto Alegre, EDIPUCRS, v. 10, n. 2, jul./dez. 2017, 
política diferenciada e compromissada com uma "real" democratização no país. A falta de uma proposta factível de democratização comprova-se com a omissão ou a passividade das lideranças udenistas diante da continuidade das estruturas repressivas e administrativas do regime contra o qual se uniram.

Imprescindível lembrar que Vargas não apoiou de imediato a candidatura do General Dutra, tendo sido dissuadido pelo empresário e líder queremista Hugo Borghi, em troca do compromisso de que Dutra nada faria para apurar os episódios de corrupção e de violações aos direitos humanos praticados por agentes do Estado Novo (BENEVIDES, 1981, p. 57).

Sobre a inevitável herança do aparato repressivo varguista, Nelson Werneck Sodré que Dutra herdou:

Começou, assim, em 1946, a duríssima repressão policial que caracterizou o período de governo do general Eurico Gaspar Dutra. Dentro dos mesmos moldes estadonovistas, assassinavam ou espancavam, nas prisões ou em público, trabalhadores, intelectuais e até chefes militares, igualados no tratamento.(sic) $)^{18}$

Cite-se, por fim, ainda a fala esclarecedora do Sr. Arthur Bernardes Filho sobre a falta de vontade política da oposição em combater institucionalmente o Estado Novo: "o chefe do Estado Novo é portador de dupla personalidade. Ninguém reconhece no Senador de hoje o ditador de ontem. A bancada da U.D.N e os representantes do P.R., o aplaudem abundantemente."19

Sobre o $2^{\circ}$ fator, alie-se à preocupação dos partidos políticos nas eleições presidências o enorme prestígio que o ditador Getúlio Vargas ainda tinha perante as classes menos favorecidas, gerando inclusive um movimento de apoio a sua permanência no poder durante a constituinte ou até mesmo ad aeternum, o chamado movimento "Queremista".

Tal movimento tinha amplo apoio popular que fazia com que manifestações populares no palácio da Guanabara de apoio a Vargas serem supostamente até encorajadas por setores ligados ao governo. O próprio Partido Comunista do Brasil recém legalizado tinha aderido também a bandeira da constituinte com Getúlio.

Michelle Reis de Macedo explica: "Contrariando as expectativas de muitos, trabalhadores e populares decidiram reivindicar a permanência de Getúlio Vargas na

\footnotetext{
${ }^{18}$ Ibidem, p.358.

${ }^{19}$ No Senado Federal. Jornal do Brasil, Rio de Janeiro, 10 de Maio de 1947, p.6.
} 
presidência da República, por crer que esta seria a melhor alternativa para garantir seus interesses." 20

Entretanto, houveram vozes que se levantaram contra a impunidade estadonovista, políticos da UDN como Euclides Figueiredo e Plínio Barreto manifestaram seu desejo de responsabilizar os agentes da polícia política varguista, o que gerou o principal (e fracassado) esforço de justiça de transição do Estado Novo varguista: a CPI chamada de "Atos Delituosos da Ditadura”.

\section{JUSTIÇA DE TRANSIÇÃO DO ESTADO NOVO}

A tentativa de responsabilização dos agentes do Estado Novo perpetuadores de crimes contra os direitos humanos deu-se principalmente nos anos de 1946-48, sendo o resultado mais expressivo destes esforços a CPI dos "Atos Delituosos da Ditadura".

Saliente-se que, aproximadamente, durante o mesmo período, no contexto transicional italiano, "Entre 1945 e 1947, houve quase 30 mil julgamentos por colaboracionismo, dos quais mais de mil resultariam em pena de morte (embora menos de um décimo das sentenças fossem executadas". 21

Esta comissão parlamentar de inquérito concentrou seus esforços nos depoimentos dos presos políticos do regime varguista e no livro "Falta Alguém em Nuremberg" do jornalista David Nasser.

Dentre estes depoimentos destacamos inicialmente o do Sr. Hermes Lima no dia 10 de Junho de 1948:

Tive contacto com centenas de outros presos políticos. Muitos dêles voltavam às celas, depois de chamados a prestar depoimento da Policia, com marcas evidentes de espancamento, principalmente, quando se tratava de elementos do Partido Comunista, ou de operários e homens do povo.

$[\ldots]$

Desejo acentuar, portanto, que as condições de legalidade em 1936 eram tão precárias que um cidadão brasileiro, com posição social e intelectual definida, podia ser retido na prisão pelo espaço de um ano, sem ser chamado a responder a qualquer inquérito, sem ser indiciado em processo algum, sem que, portanto, houvesse prova de culpa de qualquer espécie.(sic) ${ }^{22}$

\footnotetext{
${ }^{20}$ MACEDO, Michelle Reis de. O movimento queremista e a democratização de 1945: trabalhadores na luta por direitos. $1^{\text {a }}$ Ed. Rio de Janeiro: 7Letras, 2013, p.25

${ }^{21}$ TARCHI, Marco. O passado fascista e a democracia na Itália. In: COSTA PINTO, Antonio. PALOMANES MARTINHO, Francisco Carlos (Org). O passado que não passa: a sombra das ditaduras na Europa do sul e na América Latina. Rio de Janeiro: Civilização Brasileira, 2013, p.60

${ }^{22}$ Comissão de Inquérito dos Atos Delituosos da Ditadura, Rio de Janeiro, 10 de junho de 1948, p. 3-4.
} 
O depoimento mais icônico da CPI foi o do deputado Carlos Marighela, que relatou com propriedade as diversas atrocidades que a ditadura lhe cometeu, as quais transcrevemos:

[...] As torturas a que fui submetido foram as seguintes: depois de murros, ponta-pés e outros golpes que me aplicaram, fui queimado por todo o corpo com pontas de cigarros que os próprios investigadores estavam fumando. Além disso, o investigador Galvão tirou seu alfinete da gravata, que enfiou debaixo de minhas unhas, deixando-as em sangue. Em seguida, fui submetido ao chamado "aperto de escrotos"; reuniram-se todos e, através dos golpes chamados "chave de braço", fui levado ao chão varias vezes, o que me produziu um ferimento na testa.(sic) ${ }^{23}$

Conforme também apurado na CPI, era comum os investigadores da policia política, após aplicarem torturas e espancamentos nos presos políticos, levassem os detidos para hospícios e lá os internassem como loucos.

A última ata disponível da comissão data do dia 17 de junho de 1948, quando a comissão se encerra sem qualquer tipo de resultados mais consubstanciados. O Ministério Público não oferece nenhuma denúncia relacionada aos crimes ali relatados.

Finalmente, note-se que existia sim um arcabouço jurídico, como a Lei de Segurança Nacional, de 4 de abril de 1935, que dava certa guarida as atitudes autoritárias do governo do Estado Novo.

\section{Conclusão}

O objetivo do presente estudo foi demonstrar que não houve uma justiça de transição no Brasil pós Estado Novo, considerando que, apesar do governo varguista ter sido derrubado por um golpe da cúpula militar, a transição ter sido de certo modo "pactuada" entre o antigo regime estadonovista e a oposição.

Tal tese pôde ser demonstrada pelo fato de que o próprio Vargas passa a apoiar, depois de alguns contratempos, a candidatura do General Dutra a presidência, militar que inclusive tinha participado do golpe que o retirou do governo.

A UDN, principal partido de oposição ao regime estanonovista, também não buscou de forma efetiva a responsabilização dos agentes estatais que cometeram crimes contra os direitos humanos durante o Estado Novo.

A "CPI dos Atos Delituosos da Ditadura", principal esforço no sentido da responsabilização dos agentes do estado ditatorial, deve ser vista como uma forma fracassada

${ }^{23}$ Comissão de Inquérito dos Atos Delituosos da Ditadura, Rio de Janeiro, 21 de Agosto de 1947, p.17/3

Oficina do Historiador, Porto Alegre, EDIPUCRS, v. 10, n. 2, jul./dez. 2017, 
de Justiça de Transição no Brasil, considerando que os principais líderes da repressão do Estado Novo nunca foram sequer denunciados.

Procurou-se demonstrar que tal prática foi fora dos padrões internacionais, pois os países que atravessaram regimes autoritários e/ou ditatoriais, como comparado especificamente com a Itália pós-guerra, realizaram uma justiça transicional em seus países onde procuraram responsabilizar os agentes do estado ditatorial, reparar as vítimas e se distanciarem do passado autoritário.

\section{Referências}

BENEVIDES, M. V.. A UDN e o Udenismo (ambiguidades do liberalismo brasileiro). $1^{\text {a }}$ Ed. Rio de Janeiro: Paz e Terra, 1981. v. a. 297p .

COSTA PINTO, Antonio. PALOMANES MARTINHO, Francisco Carlos(Org). O passado que não passa: a sombra das ditaduras na Europa do sul e na América Latina. Rio de Janeiro: Civilização Brasileira, 2013.

MACEDO, Michelle Reis de. O movimento queremista e a democratização de 1945: trabalhadores na luta por direitos. $1^{\mathrm{a}}$ Ed. Rio de Janeiro: 7Letras, 2013.

PACHECO DA SILVA, Thiago. As duas faces da repressão: semelhanças e diferenças da polícia política durante o estado novo (1937-1945) e durante a ditadura militar (1964-1983). Revista De História Comparada, Rio de Janeiro, 2010.

PRESTES, Luiz Carlos. UNIÃO NACIONAL para a democracia e o progresso. Rio de Janeiro, 1945

SODRÉ, Nelson Werneck. História Militar do Brasil/Nelson Werneck Sodré, $2^{\text {a }}$ Ed. São Paulo: Expressão Popular, 2010

SOUZA JUNIOR, José Geraldo de. O direito achado na rua: introdução crítica à justiça de transição na América Latina. $1^{\text {a }}$ Ed. Brasília, DF: UnB, 2015.

TARCHI, Marco. O passado fascista e a democracia na Itália. In: COSTA PINTO, Antonio. PALOMANES MARTINHO, Francisco Carlos(Org). O passado que não passa: a sombra das ditaduras na Europa do sul e na América Latina. Rio de Janeiro: Civilização Brasileira, 2013.

TORELLY, Marcelo. Justiça de Transição - Origens e Conceitos. In: SOUSA JUNIOR, J. G. (Org.); SILVA FILHO, J. C. M. (Org.); PAIXAO, C. (Org.); FONSECA, L. G. D. (Org.) ; RAMPIN, T. T. D. (Org.) . O Direito Achado na Rua: introdução crítica à justiça de transição na América Latina. 1. ed. Brasília. 2015. v. 1.

ARTIGO ENVIADO EM: 15/05/2017

ARTIGO ACEITO PARA PUBLICAÇÃO EM: 20/12/2017 